\title{
Dialogic Multicultural Education Theory and Praxis: Dialogue and the Problems of Multicultural Education in a Pluralistic Society
}

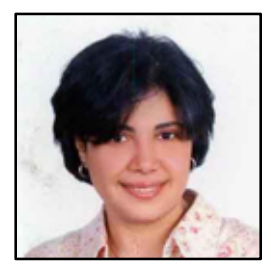

Nermine Abd Elkader

University of Delaware

\begin{abstract}
The purpose of this theoretical article is to highlight the role that dialogic pedagogy can play in critical multicultural education for pre-service teachers. The article starts by discussing the problematic that critical multicultural education poses in a democratic society that claims freedom of speech and freedom of expression as a basic tenet of democracy. Through investigating research findings in the field of critical multicultural education in higher education, the author argues that many of the educational approaches-including the ones that claim dialogue to be their main instructional tool- could be described as undemocratic, and thus have done more harm than good for the multicultural objectives. On the other hand, the author argues that dialogic pedagogy could be a better approach for critical multicultural education as it promises many opportunities for learning that do not violate the students' rights of freedom of expression and freedom of association. Throughout this article, the author tries to clarify the difference between dialogic pedagogy and other conceptualizations of dialogue in critical multicultural education arguing for the better suitability of dialogic pedagogy for providing a safer learning environment that encompasses differing and at times conflicting voices.
\end{abstract}

Nermine Abd Elkader has recently graduated with a Ph.D. degree in the Sociocultural and Communal Approaches in Education at the University of Delaware. She is currently working on a research project that involves the professional development of in-service teachers who wish to follow the dialogic approach in their classrooms.

$\cos 8080$ 


\section{Introduction: Multicultural Education as a Democratic Movement for Education Reform: Could a Movement that Claims Democracy as its Basic Tenet be Anti-Democratic?}

There is a dilemma that multicultural education for pre-service teachers has to deal with: it is that of democracy, pluralism, and the struggle among different voices in the society for and against multiculturalism. The dilemma is caused by the fact that while many educators regard the goal of multicultural education policies and practices to be social justice and equality for minorities (LadsonBillings, 1999; Nieto, 2004; Yosso, 2002), fulfilling the multicultural requirement in teacher education programs is a mandate for all students (Yang \& Montgomery, 2013) even those who have no intention to work with minority students and those who might not believe in the multiculturism and pluralism of the society in the first place.

As a policy that is imposed on all students, the multicultural objectives, especially those concerned with antiracist education (Lee, 1995; Sleeter \& Bernal, 2003), provoke the resistance of the majority of the students-especially those who are White and middle class (Ladson-Billings, 1999; Solomon, Portelli, Daniel, \& Campbell, 2005). This is in addition to the fact that any success that the multicultural course might achieve in reducing prejudices and changing negative stereotypes about minorities during the time of the course is short lived and difficult to sustain in the long term (Holins \& Guzman, 2005). This suggests that such superficial success only reflects students' desire to give instructors the answers they are looking for without actual changes in the students' convictions or perceptions. Such findings raise red flags about the worth of a multicultural education that could not sustain its learning outcomes for long. Moreover, besides the futility of multicultural education if students do not see its relevance or credibility, could multicultural education with its insistence on certain curricular endpoints that are already contested in the public discourse be anti-democratic obliterating the voices of students who do not agree with its learning objectives? Could the multicultural curriculum be imposing on the students the pre-pondered and the pre-packaged answers of policy makers and teachers? Finally, could a monolithic discourse in multicultural education, even if it were for a good cause such as social justice, be as oppressing to the pre-service teachers as conventional education is to minority students who do not conform to the school's culture or to cultural codes as defined and approved by the school (Delpit, 1995; Fordham, 1993)? In this paper, I argue that dialogic pedagogy, as conceptualized by Bakhtinian scholars, could potentially provide an answer to this dilemma. In a democratic and free multicultural class, the role of the educator is to encourage the students to explore, investigate, and examine different views and perspectives including both the authoritative word of politics, ideology, and religion, and the internally persuasive discourse arising from other class members' subjectivities, opinions, experiences, and struggles with the topics. I propose that dialogic pedagogy is different from approaches that have been used in many multicultural classes that claimed dialogue or rather critical dialogue to be the main instrument of instruction (Amos, 2010; Delpit, 1988; Martin, 2010; Solomon et al., 2005). The alleged collapse of dialogue and the proclaimed failure or little success of the multicultural praxis in these classes could be due to a conceptualization of dialogue that radically differs from Bakhtinian dialogic pedagogy. In what follows, I will examine historical and contemporary dialogic approaches in critical multicultural education highlighting the challenges that they posited for a free and democratic dialogue.

\section{Dialogue in Critical Pedagogy}

Much of the discourse on multicultural education has conceptualized it as an antiracist education (Ladson-Billings \& Tate, 1995; Lee, 1995; Nieto, 2004). By antiracist education, multicultural educators 
emphasized the importance of advancing a social justice agenda in teacher education programs and invited educators to lead their pre-service teachers in an examination of their racial identity, the privileges of their White middle class status, and the subordination, socioeconomic disadvantage, and inequitable access to opportunities that such privilege caused to other groups (Lee, 1995; Sleeter, 1995). Antiracist education not only challenges conservative views that call for assimilation to Eurocentric norms, language, and culture (Bennett, 1992; Hirsch, 1987), but also liberal views that claim that all people groups in the society have access to equal opportunities in education and that hard work and meritocracy are the only basis for success in the American society (Delgado \& Stefancic, 2011). In an attempt to target prejudices against minorities, different paradigms of multicultural education with antiracist orientation sought to discuss negative stereotypes about minorities that have been circulated in the public discourse by the aid of the media, the law, and the political arena (Solorzano, 1997; Stovall, 2004; Taylor, Gillborn, \& Ladson-Billings, 2009). Such paradigms were also meant to show pre-service teachers that stereotypes affected how teachers perceived their minority students in a way that impacted these students' school success and achievement. Despite the plethora of research studies that promote antiracist multicultural education in teacher education programs and that proclaim the value of the experiential knowledge of teachers and students of color in introducing White pre-service teachers to an alternative epistemology and alternative curriculum that their formal mainstream education never addressed (Kohli, 2008; Yosso, 2002), antiracist multicultural education has been faced with many challenges and many setbacks in teacher education to the extent that Martin (2010) proclaims that faculty who teach such courses often feel disappointed, drained, and in need of self-replenishing after the courses are over.

One of the biggest challenges of the anti-racist paradigm in multicultural education is the students' resistance to it. Such challenges were reported for anti-racist multicultural education, anti-sexist (DePalma, 2007), and anti-homophobic multicultural education (Whitlock, 2010); however, with the last two, students' resistance was presented as being more vocal and more explicit than their resistance to racial conversations. For example, Milner (2008) and Ladson-Billings and Tate (2006) maintained that when racial issues were raised, White students often resolved to silence and disengagement. LadsonBillings et al. (2006) raised the concern that such silence could be deafening to the extent that it could in turn silence students and teachers of color on racial issues. However, by listening to some students talk about the racial discourse outside the classroom, Ladson-Billings et al. (2006) discovered that such silence hid behind it strong feelings of anger, resentment, and insecurity. These strong emotions were not just specific to White students. Students of color, too - particularly Black students - expressed the same feelings, though more explicitly, for being put in a position of having to teach Whites about things they should have already known. Likewise, Milner (2008) explored the issue of White students' silence on the discourse of racism and maintained that it often felt intimidating to the instructors especially those of color. Ladson-Billings et al. (2006) believed that educators should encourage their students to be more vocal and to voice their feelings and opinions and not to just assume that their silence emerged from a position of consent or ignorance of the topic. On the other hand, Milner (2008) took a different stance calling for a political action and solidarity among likeminded educators to effect change in the multicultural curriculum of the entire academy. Milner's recommendations besides Ladson-Billings et al.'s (2006) findings bring up the question of which direction multicultural education policies should take in a democratic society, and if policy could be so radicalized that it could hinder democracy and pull in the other direction of traditionalist conservatives with both parties envisioning a reality in which only their version of a good citizen and a good society should exist.

Another question that presents itself is if students' resistance to the critical multicultural discourse arises from a place of ignorance, strong emotions of guilt, and resentment and anger toward accusations 
of racism and privilege (Milner, 2008; Solomon et al., 2005) or whether it arises from a place of personal convictions deeply rooted in political or even religious ideology? If the latter is the case, at least in some of these cases, could a multicultural curriculum that insists on producing the results of prejudice reduction, identity examination and re-construction, and social action be a totalitarian project calling for conformity rather than diversity and democracy?

Kukathas (2003) maintains that the problem of diversity in a free and liberal society emerges when the State is allowed any role in determining what a good life for its citizens should look like or should not look like. Within the context of diversity, assuming that the state should have any authority in imposing equality among all groups is inherently anti-democratic. Kukathas (2003) sets the social justice agenda against diversity and claims that striving for equality creates an egalitarian system that suppresses and intentionally oppresses diversity. According to Kukathas (2003), diversity necessarily entails inequality; and the assumption that multiculturalism entails fighting for equality is unrealistic and erroneous. For example, equality might not be a value cherished by certain communities within a society that seeks it. To mention a few, Kukathas illustrates that the Amish in the US, the Indians in Brazil, and the aboriginal people of Malaysia are more likely to be indifferent to political equality and sharing power; in fact, many of them have no desire to embrace it and are considered as victims of those who try to bring them forcibly into it.

Similarly, Kukathas (2003) opposes a liberal theory that mandates the State to uphold justice because in such case, justice would be defined according to liberal values and thus eliminates any other definitions or conceptions of justice that do not agree with the liberal views which in turn affects diversity and suppresses it. Case in point: while Kukathas (2003) maintains that diversity should not and could not be sacrificed in any liberal and free society, he does not think that it is compatible with equality or with a single definition of what constitutes social justice. He would, thus, rather sacrifice these two for the sake of diversity. A theory in multiculturalism in this case would therefore look at diversity as a human condition that is reliant on individual and group characteristics and risk aversion. The two latter factors will create differences among individuals, groups, and societies making some wealthy, some bigger in size, and some die out completely. Moreover, the role of the State in such case is not to ensure equality but to ensure tolerance and the freedom to associate with any group membership that an individual should desire. The concept of group association will present one plausible solution to the problem of minorities being ostracized by their own group members when they demonstrate cultural traits and cultural preferences that are more in congruence with the mainstream culture than with the culture of their own communities (Fordham, 1993; Fordham \& Ogbu, 1986; Ogbu, 2008).

In teacher education programs, however, multicultural education has often taken that trend that Kukathas fears would be detrimental to diversity. Many of the research studies that investigate undergraduate or even graduate students' attitudes (Amos, 2010) toward multicultural courses have not taken into consideration these students' voices, personal growth, past experiences, subjectivities, or even the effect of the authoritative word of politics, religion, and past education on how they reflect on and process the controversial topics that the multicultural course exposes. For example, Solomon et al. (2005), recommend that teacher educators in multicultural education should regard their role in effectuating an education for democracy as "equitable, socially just, and prepare society's citizens to become active participants in the human community...As such, teachers' conceptions of democracy as it relates to notions of citizenship (which are intricately linked to discourses of race, racialization and belongingness), need to be examined" (p. 148). The political undertone of the last statement cannot be overlooked and does not take into account the value of democracy as respecting differences and human agencies. Similar language can be found in other paradigms of critical multicultural education that call for 
identity deconstruction/reconstruction, interrogating Whiteness, decentering Whiteness (Bergerson, 2003; Holins \& Guzman, 2005). They all seem to impose a political and partisan agenda in multicultural courses that contradicts the tenets of democracy that multicultural education seems to be calling for especially when these courses are offered as a core requirement for a degree program.

Politicizing the multicultural curriculum could be a reason for the proclaimed ineffectiveness of the movement (Mattai, 1992). However, considering any educational project as neutral and without political implication is both unrealistic and harmful. Cuenca (2010) argues that apoliticizing education especially in the field of social subjects with their emphasis on civic and citizenship participation might lead to the apoliticization of democracy in schools reducing citizenship to mere "good" civic deeds and producing a form of citizenship unable to develop voice or to question the government on big issues such as federal spending and health care. In fact, any monolithic discourse-on either ends of the spectrum- might lead to students' resistance and might harm democratic education rather than reform it; thus emerges the importance of dialogic pedagogy in providing an answer for the problem of diversity and democracy. Yet, Bakhtinian dialogue should not be confused with Freire's dialogic philosophy, which could easily happen since both approaches emphasize the students' role in dialogue as subjects who define their own goals and drive their own learning project. However, the author contends that while Freire's dialogic approach could proclaim democracy and emancipation, a clearer examination of this paradigm reveals it to be problematic and potentially oppressing to both teachers and students in a diverse setting.

\section{Freirean vs. Bakhtinian Dialogue: For or Against Democratic Education?}

A problem with any dialogic project that has an end goal is how power relations could limit and hinder its authenticity and the ability or even safety of the students and educators who engage in it. Much of the discourse on multicultural education is grounded in the work of critical pedagogues such as Freire and Shor (Nieto, 2004). Both scholars claim dialogue as the basis for democratic and emancipatory education and argue against a banking education that treats students as vessels of the system's attempts to use them according to the whims and needs of the dominant power (Freire, 1993; Freire \& Macedo, 1987; Shor \& Freire, 1987). In the Freirean dialogue, it is proclaimed that students should presume the role of subjects (Freire \& Macedo, 1987) who partner with the educator to set the goals, directions, and even assessment criteria and procedures of the curriculum (Shor, 1992). However, in reading Freire, one could not overlook the wide gap between theory and practice.

Freire's (1993) cultural circle was meant to raise the Brazilian peasants' critical awareness of their oppressed situation and the positions of dominance and privilege that the nobles had over them. These cultural conversations had the goal to create literacy among the peasants that would lead to revolution for liberation. In other words, Freire's literacy paradigm was meant to alert the peasants that their position under the oppressor was not pre-determined and that it was changeable relying on how they view themselves as historical humans and not as existential animals with no heritage (Freire, 1993). However and despite the apparently empowering Freirean literacy theory, a concern regarding it is that it does not have an answer for the issue of diversity especially that of students' voices within such paradigm. Freire's failure in Guinea Bissau highlights the relevance of this issue: what happens when students and teachers do not agree with each other on the end goals of their dialogue? Facundo (1984) ascertains that tens of ethnic groups existed in Guinea Bissau post the revolution, many of whom had a policy of complete segregation and thus did not have a direct contact with the colonizer and in turn with oppression as presumed by Freire. Besides, with Freire's persistence on reaching out to all people's group in Guinea Bissau, he might have overlooked the economic reality of some of these groups which relied heavily on agriculture and thus might have not seen any value in literacy (Facundo, 1984). Freire proclaimed (Freire \& Macedo, 1987) that his literacy program had failed in Guinea Bissau because of the government's 
insistence on using the Portuguese language which was the language of the colonizer and thus might have sacrificed the interests of the larger student population in the society who spoke their ethnic languages and could not learn Portuguese. However, such evaluation did not include the voices of the stakeholders in that project. We only hear a subtle voice for the country's revolutionary leader and thinker, Amical Cabral, expressing his dilemma over the many ethnic languages that the country had, and emphasizing his belief that the only answer he could deem for the problem was to use Portuguese as a unifying language for the nation. However, Freire acknowledged Cabral's voice only after the program had already failed. Freire himself (Freire \& Macedo, 1987) confessed that at the time of his involvement in Guinea Bissau, he did not know Cabral's reasons for his insistence on Portuguese as a language of instruction. Besides, Facundo (1984) worries that Freire blamed the failure of the volunteer workers on their lack of training and motivation to help the oppressed without considering other minor reasons that had nothing to do with ideologies; for example simple logistics such as hard and unsafe transportation and lack of access to printing and copying material could have had negative effects on workers' motivation and productivity and thus on the attrition rate. For all intents and purposes, although Freire wanted to spend months in Guinea Bissau conducting interviews about Amical Cabral (Freire \& Macedo, 1987), we hear no such similar desire on his part regarding the students of Guinea Bissau or their educators. All the above could suggest that some reasons for the gap between theory and practice in Freire's approach is his totalitarian approach to education that proclaims the subjectivity of the other in theory but ignores it in practice. In fact, when asked about how he could deal with the problem of diversity in the educational context, Freire could not give a clear cut answer. In Guinea Bissau, he kept emphasizing the shortcoming of the country's leadership in insisting on using Portuguese. In the United States, Freire refused to give what he proclaimed to be a prescription for educators, which suggests that he could have evaded a problem that he had no answer for. Thus, while Freire (Freire \& Macedo, 1987) promoted his literacy model as universal, in practice, it did not work as was proposed when the context changed and became more diverse.

From a dialogic pedagogy standpoint, one could anticipate that within the Freirean paradigm, the student-teacher relationship broke down when the literacy project finalized the student population too early and treated them as predictable finalized beings who needed to attain a curricular end point predefined for them. Since much of the work of critical multicultural educators in the United States have been impacted by Freire (Facundo, 1984; Nieto, 2004), we can hypothesize that the monologism of the Freirean paradigm has something to do with the challenges and acknowledged failures they met in their program (Holins \& Guzman, 2005).

\section{Dialogic Pedagogy in Multicultural Education: Theoretical Framework}

Many of the conceptualizations and pedagogical approaches of critical multicultural education could be viewed as monologic according to a Bakhtinian conceptualization of dialogue (Bakhtin, 1991). Dialogic pedagogy scholars (Sidorkin, 1999; Sullivan, 2011) argue that a true human dialogue engages the other in a relationship where answers remain between the dialogic partners rather than outside them and where the author while interpreting the word of the other reflects on how he/she has been a part of this interpretation. Sidorkin (1999) expresses this relationship as the self being at the boundaries of a social and dialogic relationship with another. Dialogic pedagogy scholars have thus realized a deficit in multicultural education pedagogy that did not take into account the dialogic relationship that needed to exist between teachers and students for any learning to be humane, realistic, and transformative (Madison, 2011; Matusov \& Smith, 2007); hence, from a dialogic pedagogy perspective, there emerges a need for an approach in critical multicultural education that engages both teachers and students, as well as their future stakeholders, in a dialogue that respects their final stance on any issue even if or especially when this means disagreement among those involved. I contend that critical pedagogy that 
seeks to prepare critical citizens for a democratic society should also accept learners who end up disagreeing and even acting against its own project. In doing so, educators could have the right to believe education to be a political project and to express their subjectivity within that project. However, they do not ignore that from an ethical and a democratic standpoint, no teacher should impose on the students any side or view; in fact, according to Sidorkin (1999), a teacher should discourage a student from taking any side too early in life and they should leave it up to them to be the final judge of the truth. In Sidorkin's words, "Learning in itself is an exposure to complexity. The school may teach the evolutionism and creationism; the variety of different religions and atheism; the 'rainbow curriculum' and 'family values'. The double message is, in fact, the only truly educational message" (Sidorkin, 1999, p. 125). According to this perspective, therefore, monologism could be a significant threat to any successfully free and democratic educational project whether it be in multicultural education or otherwise.

Monologism is two folded. It is the contention that there is one ultimate truth which can be attained through consensus in a free dialogue; and it is the conviction that truth pre-exists, is pre-defined, and has been previously achieved (Sidorkin, 1999). Therefore, Freirean and critical pedagogy dialogues, despite their alleged promotion of students' engagement in a free and open discussion, could represent an educational project that is anti-dialogic and that has major ontological harms (Matusov, 2009). Alternatively, Matusov (2011) maintains that teachers need to bring to the discussion their personal convictions, passions, and ideologies as long as the discussion is a two-way or taking the nature of a diversity class into consideration- a multiple way conversation where all voices are heard and legitimized as valid to exist outside the power or hierarchical relationships of the institution that might suppress differences and hinder the authenticity of the dialogue.

Based on the above, students' resistance in the multicultural courses could be interpreted as a breakdown in the communication between students and teachers and students and one another. Sidorkin (1999) maintains that although resistance in a classroom context could be interpreted as behavioral dysfunction, most of the time, resistance is some sort of students' agency responding to those who through monologism deny students' voices the right to exist. For example, Skidmore (2000) found a breakdown in the dialogue between the teacher and one of her elementary school students in a reading class when the teacher tried to impose on that student an answer, which she [the teacher] perceived as the right answer. Interestingly, when the breakdown took place, it was not just between the teacher and that specific student but it was between that teacher and the whole class. Although the teacher herself blamed the class for behavioral problems that caused the breakdown, Skidmore (2000) proclaimed that it was the teacher's insistence on a monologic answer provided by the textbook as the only right answer that caused the breakdown. Similar results were found in a study of a science class in which students' power in dialogue was shown to combat the teacher's authority and even the authoritative knowledge presented by the textbook (Candela, 1999). In that lab experiment, the teacher asked the students to confirm certain results for an experiment she prepared for them to conduct. When a student challenged the results expected by the teacher, and the teacher insisted on her pre-set goals without listening to the student, the whole class ended up in a state of silence in which the students stopped talking to one another and to the teacher, and stopped responding to the teacher's direct and indirect questions.

Matusov (2007) fears what he deems as teacher's objectification of the students in which students become the objects of the teacher's fantasies, aspirations, and expected or imagined outcomes. This issue is relevant when we consider that the goal of a critical multicultural project is mostly for social justice, transformation, and equity pedagogy (Banks, 1994). When teachers take the approach of excessively objectifying their students without investigating their students' subjectivity, perception of the world, and ways of knowing, they resemble a computer designer who complains about a problem with a 
machine and not with actual human beings (Matusov, 2007). Such dehumanizing of students contradicts what Freire's emancipatory literacy project is proclaimed to set out to achieve i.e. the humanization of both the oppressed and their oppressors (Freire, 1993). On a similar note, Sidorkin (1999) maintains that while many studies might claim that the dialogue between teachers and students fails for cultural reasons, often the reason is more relational than cultural. Matusov (2003) alerts us to the dualistic psychology of the discourse on culture; when people's differences (and cultures) are ignored in dialogue, misunderstandings happen and dialogue breaks down, but also when dialogue breaks down because of misunderstandings, people are characterized as cultural. Therefore, Sidorkin (1999) maintains that reducing dialogue to the level of mere communication among people is counterproductive to its role in effectuating learning. Sidorkin (1999) maintains that learning takes place when a tension happens between the authoritative word that people bring into the dialogue (this usually comes in a whole unit packaged by the authority of religion, ideology, political power, and cultural values) and the internally persuasive discourse which is the word re-told in one's own word and thus appropriated and modified to reflect one's own subjectivity in interacting with both the authoritative word and the word of another. Thus, relationships among teachers and students and students and one another could not just be explained in simplistic terms as many of the studies of multicultural education have shown them to be i.e. in terms of racial tension and White privilege, but they also need to be investigated in terms of students' agency, subjectivities, and past relationships with members of their own racial and ethnic groups, members of other groups, and the authority of the institutions and the educators. This kind of investigation reveals the complexity of students' learning through participation in dialogue rather than homogenizing all White students as privileged due to their dominant status and as resistant to change the status quo.

Students' agency and subjectivity thus emerge as an important opportunity that dialogic pedagogy can present for free, democratic, and authentic learning. I will explore this issue more in what follows highlighting why human agency is relevant to a democratic discourse on multicultural education.

\section{The Relationship between Human Agency, Dialogic Pedagogy, and a Democratic Multicultural Education}

Ladson-Billings (1999) proclaims that unless pre-service teachers see some significance for the multicultural project in their future careers, it is unlikely that multicultural education could affect any change in pre-service teachers' learning and instructional practices. According to Ladson-Billings (1999), one of the most significant motivators for pre-service teachers to learn about multiculturalism is their desire to succeed with their future students and to avoid burnout and public embarrassment caused by problems of classroom management. Thus, many pre-service teachers enter the multicultural course with a desire, at least a proclaimed one, to know and understand their diverse students (Holins \& Guzman, 2005). Teacher educators should, therefore, structure their multicultural courses to take advantage of this initial interest. Matusov (2011) proclaims that this could be done by allowing students' agency to author their own learning.

According to Matusov (2001), agency "involves processes of developing and prioritizing goals, problems and choices, problem solving, and making and realizing solutions (including moral ones). By this definition, the notion of agency has inherently a sociocultural nature, since the final cause of an individual's actions always has a distributed character in time, space, meaning, and among direct and indirect participants of the activity" (p. 369). For students to be able to collaborate together toward a successful learning experience, they need to form among one another a community of learners. The community of learners recognizes the need of its members for one another not to reach common goals, but rather, because they acknowledge one another's dialogic agency in developing one's views and 
values even when in conflict. This is not to say that members of the community of learners will always disagree about their common goals; instead, this suggests that the teacher in this role will recognize his or her responsibility to provide guidance and to accept and even appreciate differences and disagreements. Moreover, when the challenge arises with students who have no desire to learn and no interest in the multicultural course, an authentic dialogic project would recognize the students' agency even if it were against participation (Brown \& Renshaw, 2006), and so does democratic education according to Kukathas' (2003) liberal theory.

Besides, an authentic dialogue could not be limited to the time and space of the classroom. Research studies (Fecho, Collier, Friese, \& Wilson, 2010; Matusov, Hayes, \& Pluta, 2005) have shown that dialogic pedagogy, as a human activity, often times requires a dialogic space and time that goes beyond the chronotope (the intersection between time, space, and the approved values and traditions) of the classroom. Ellsworth (1989) realized that need when she feared that dialogic pedagogy across differences might turn into mere rationalization but not ontological or ideological change (in the context of her study) or even worse into another form of repression where the participants become radicalized into an "us-ness" against "them-ness". She also feared that voices in the class were similar to voices in the society and thus might have not carried equal legitimacy, sense of safety, and power in dialogue. In her study, affinity groups formed among students who did not feel empowered enough to "speak back" or tell of their own experiences with racism and oppressions. These affinity groups met outside the class time and shared potlucks, field trips, and cultural discussions of their experiences. Then these groups decided to state their voice to the class not as individuals but as members of a social group and they decided that this would not be in a dialogue form but in a way of sharing while silencing the other as they had traditionally been silenced. Bakhtinian scholars might disagree with the concept of silencing under any circumstances besides they might interpret affinity groups as excessive monologism which I will discuss later. Nevertheless, Ellsworth's (1989) study confirms the realization that any authentic dialogue would need to continue beyond the time and space of the classroom and to engage members of a wider community than that of the class. Elsewhere, Matusov et al. (2005) and Fecho et al. (2010) provided this space through class websites where students could "chat" about the topics of the curriculum. Matusov et al. (2005) maintained through discourse analysis that students' contributions were only $3 \%$ social in nature, and that most of the students' postings were an extension of the topics discussed in class. However, the fact that students also used the class web for social communication indicated how the class dialogue penetrated their everyday activities as opposed to the traditional class discussion where the class space and time are separated from the wider activities of students' lives. Similarly, Fecho et al. (2010), sharing students' contribution during a class on critical literacy, suggested transformation in the students' subjectivity through dialogic pedagogy that extended beyond the classroom setting. In this case, students' own reflections on their students' writings and on one another's writing led to major life changing decisions for some. For example, one of the research subjects through dialogic pedagogy had her attention directed to the mutual lessons that could be learned by teachers and students as they engaged in the dialogic journey. While she criticized one of her Middle Eastern students for allowing her family to dictate her life, she discovered that within her own religious community, her lived experience might have not differed much from her student's. That teacher thus had to embark on her own self- discovery and self- identification journey that ended with her denouncing her religious organization and accepting a position in life that could be transient or permanent by putting her religious belief under investigation and thus separating herself from her own community.

Thus, providing a venue beyond the classroom boundaries ensured the continuity of dialogue through students' authorial learning - an aspect of students' agency (Matusov, 2011). Matusov (2011) defines students' authorial learning as the opportunity that students have to "realize themselves, define 
their own voices; address and respond to others; engage and transform the culture; define new goals; develop new desires and interests; take responsibility for their actions, opinions, views, and values; reply and address voices of relevant and important others (living in past and now)" (p. 36). Students' authorial learning can be both responsive authorship and self-generated authorship and the teachers should be able to promote and support both types of authorship for learning and teaching to be successful. Both Matusov at al. (2007) and DePalma et al. (2006), therefore, believe with antiracist educators that minority students should be authors of the multicultural curriculum because they could teach pre-service teachers valuable knowledge about their lives and about their education; however, they might differ in their conceptualization of the role of opposing students in such paradigm. I would expect dialogic pedagogy authors to desire mainstream students as well to provide material for the curriculum even when this material is in direct opposition to the objectives of the multicultural course.

The significance of educators' legitimizing the voices of all students is that as an authentic human activity (Matusov, 2009; Sidorkin, 1999), dialogue cannot be turned on and off as the situation requires it. Dialogue could be suppressed and students' voices could be muffled by the dominance and sometimes tyranny of the authority but this does not mean that it is not taking place. One example of that is provided by Sidorkin's description of the three discourses that take place at a school setting. While the first two discourses reflect formal ways of communication that could start with lecture or presentation followed by a discussion that is usually instructional and highly structured by the teacher, the third discourse in which the class breaks up into clutter and chatter and students engage in unstructured and unguided conversations could be the time when true learning happens; it is this time that students informally author their own learning. This third discourse could be found whenever educators allow students to interact about the topics of the curriculum in a safe environment but it also takes place even when educators do not allow it. Bakhtin analyzed the Renaissance carnival with implications for education - though not directly linked. Carnival was a time for birth, creation and rejuvenation (Gardiner, 2002); it was also a time when language emerged into new forms away from its tight traditional structure to be rebirthed into new meanings even in its most conceivably obscene form. According to Gardiner (2000), the success of this new birth was owing to it happening away from the eyes of the officialdom. In the context of conventional education, therefore, and despite the institution's dire attempt to create structure, conformity, and standardization (Caldéron, 2006; Giroux, 2010), students can always find a time and place away from the eyes of "officialdom" (Gardiner, 2002, p.51) where they could engage in a constant dialogue that leads to social critique and even perhaps rebellion against the conventional codes of etiquette, propriety, and the monolithic seriousness of officialdom. In the context of multicultural education, carnival could represent a significant challenge to any pre-defined multicultural objective, and could be why educators have found that resistance was not individualistic but rather more of a group resistance; besides even though researchers report that minority students felt either hurt or intimidated by their White peers' attitude and comments (Amos, 2010; Solorzano, 1997), they did not feel that their White peers meant them any harm personally or intentionally (Amos, 2010); which suggests that this kind of resistance among White students built in solidarity and unity (probably in private conversations outside the tight surveillance of the course instructor) was actually directed against attempts to muffle their voices or impose upon them an agenda they did not choose.

Matusov (2009) describes this group resistance as excessive monologism. Excessive monologism could take place even when authority or, in this case, educators are not involved. Members of the same community or who are likeminded could form alliances to affirm one another's views and values and to have a strong voice. In the absence of other voices to counteract these alliances, one might wonder what learning, if any, could take place. DePalma (2010) tried to deal with this issue by inviting members from the communities that the class discussed to be guest speakers. However, DePalma's 
struggle to bring polyphony in her class was constant. Despite the fact that a one-time opportunity to invite the LGBT group on campus offered fresh ideas and new perspectives on the topic of antihomophobic education that her authoritative word and that of the texts she chose did not reveal, DePalma was aware that the fact that she was the one who chose the guest speakers and facilitated the logistics of their coming to class still reflected her authority rather than the students'. The second aspect of students' authorial learning - namely students' generative authorship could provide an answer to this problem. Students' generative authorship allows them to bring up issues and questions, and problematize conventional knowledge to allow for more provocations for the dialogue. However, the issue of voice and representation in dialogic multicultural education needs more investigation especially within the context of students' generative authorship.

In the context of multicultural education, a number of studies (DePalma, Santos Rego, \& del Mar Lorenzo Moledo, 2006; Matusov \& Smith, 2007) suggest that the most successful dialogic experiences took place in after school programs where hierarchy and authority among pre-service teachers faded away from the school context. This out of school context allowing pre-service teachers and school children to dialogue in a free setting away from the surveillance of the authority and the pressures of teaching for the test benefited the pre-service teachers in such a way that helped them learn about their future student population and reduced their prejudices against these students and their communities when they came to discover through collaboration in different projects that minority students might have certain strengths that they (the undergraduate students) and their peers did not have. For example, Matusov and Smith (2007) found that their pre-service teachers spoke about their Latino population before meeting them as objects of their own imagination; they either romanticized them or demonized them but once they came into contact with them and had the opportunity to engage them in an authentic dialogue, they started to discover true problems that they might face with their future students apart from any imagined discourse. One of these problems was surprising to the undergraduate students because it was not talked about in the grand narrative about Latino students; this was the problem of trust. Undergraduate university students came to realize that the Latino students in the center did not have much trust in the teachers and the school administration and thus would not go to their teachers if they needed help. They also came to realize that while peer pressure had an impact on that group of students, they usually would take their parents' advice over their peers. DePalma et al. (2006) assert that such out of school experiences could have a long term effect on pre-service teachers creating inside them nostalgia for success: one day when they graduate and get jobs in public schools, they could remember a time when they worked with students from a minority background, were successful with them, and were productive with outcomes that reflected true learning. Moreover, I contend that such dialogic encounters offer a first step answer to the issue of representation away from the stress related to institutional power and students' discussing absent communities in the artificial setting of the classroom. DePalma et al. (2006) maintain that learning projects should be planned and structured by educators to allow for dialogue to occur naturally while pre-service students and school children collaborate, disagree, negotiate, and resolve their disagreements. In both of these studies, students' voice and agency (whether these students were the pre-service teachers or the school children) were given priority over the curriculum. Although educators designed these activities to engage both groups of students, the end point of learning was not pre-determined, but rather depended on students' authorial learning.

\section{Toward a Theory of Dialogic Pedagogy in Critical Multicultural Education}

Dialogic pedagogy, from a Bakhtinian perspective, and as outlined by Bakhtinian scholars (Gardiner, 2002; Matusov, 2009; Morson, 2004; Sidorkin, 1999) offers a vehicle for different views and perspectives to be tested and contested without any party imposing their agenda, political or social, on the other. At the end of the day, making curricular and instructional decisions in a democratic society 
should be in the hands of both teachers and students (Shor \& Freire, 1987); however, as Giroux (2010) maintains, whereas faculty should have the choice of promoting their political or social justice agenda while teaching, students should also have the choice to reject or accept this agenda.

One of the most significant opportunities of such an approach is polyphony. Dialogic pedagogy students participate in the dialogue in a way that encompasses the authoritative word of the text, the teacher, and their own ideologies while also have the opportunity to engage the word of another granted that they have enough access to that word. DePalma (2010) is concerned that the instructor's voice is hegemonic in the educational institution since textbooks and learning materials are chosen by him/her and are subject to his/her own subjectivity and curricular goals. The studies and approaches that have been previously discussed in this article suggest that critical multicultural education often represent the views and perspectives of the instructors conducting any specific course and they often reveal one side of multicultural education and ignore other sides that extend it or disagree with it. However, within dialogic pedagogy, this hegemony is counteracted by polyphony and students' authorial learning.

For example, DePalma (2010) recommends using texts about similar topics that expose different viewpoints as well as inviting guest speakers to the class who are members of the communities that the class talks about. In this context, DePalma's (2010) guest speakers from the LGBT community provided a level of polyphony, in her study, exposing the broad diversity among members of that group. Polyphony goes beyond the presence of multiple voices in the class. Gardiner (2002) expresses Bakhtin's conceptualization of polyphony as follows: "just as no single voice can constitute polyphony, no one viewpoint can be adequate to the apprehension and understanding of the object. In order fully to conceptualize the object in its totality, that is to say, a multiplicity of perspectives or vantage-points is required" (p. 94).

Dialogic pedagogy, with its emphasis on polyphony and students' agency deals with another challenge that critical multicultural educators reportedly faced in teaching these classes i.e. their concern with the power dynamic in such courses. Some White instructors expressed their concerns about sharing their experiences for fear of recentering Whiteness and preventing the voices of minorities already weakened by the society from receiving adequate and rightful focus (Bergerson, 2003; Ellsworth, 1989). However, in DePalma's study (2010), she maintained that she, being an instructor who shared the ethnic and socioeconomic background of her students, did not shy away from sharing her White experience because dialogic pedagogy allows for these experiences to interact and collide with those of the texts and the students. Other educators from a minority background feared that their students had more power over them especially when they responded with an attitude of silence and resentment (Chávez-Reyes, 2010; Milner, 2008). The issue of polyphony and students' authorial learning should move the burden of representation either of self or other from the instructor to multiple sources and thus minimize threat and students' resistance.

Moreover, students' authorial learning promises sustaining effects especially that students' ontological engagement in the dialogue make it relevant to different aspects of their lives and their future practices. This directly challenges conventional methods of assessment that focuses on quantification, standardization, and measurement. In dialogic pedagogy, transformation to the objectives of the course might not happen or might happen as a byproduct of the learning that takes place within the internally persuasive discourse of the class. Besides, transformation might not take place immediately but through continued dialogue in students' subsequent field placements or even with other stakeholders and members of the wider society; however, Matusov (2009) contends that the real achievement for learning is that the individual cannot claim innocence or ignorance for their practices. Therefore, within the dialogic 
project, the educators should regard their main role as facilitators of learning rather than as executives of the policies of the institutions, as trainers for the employer, or as leaders of their own social movement.

Finally, dialogic pedagogy safeguards critical pedagogy from appropriation into any specific political agenda. Since dialogic pedagogy exists on the boundaries of the subjectivities of those involved in it, teachers cannot claim ownership of the educational outcomes, rather students are more authoritative in claiming that ownership and in guiding their own learning. Hence, we can expect more sustainable effects for multicultural education since students' engagement in such a project becomes ontological and develops within a process of becoming (Morson, 2004).

However, dialogic pedagogy is not void of challenges. These challenges together with the opportunities that such an approach present need to be investigated more closely to be able to fully theorize it. Matusov (2009) poses the problem that dialogic pedagogy with its emphasis on language and speech could be potentially culturally insensitive favoring one culture that might be more vocal than another. DePalma (2008) maintains that the one Black student she had in one of her multicultural classes was uncomfortable to voice her opinions on race and racism in a class where she felt powerless and a numerical minority. Moreover, Casey (2005) warns that the ideology of dialogue in its current form of implementation in higher education through seminars is a middle class value that might stymie low class students who might come to the institution under-prepared to participate in a dialogue especially in the field of humanities. Sharing about oneself and one's communities among a majority of middle class students could also be embarrassing to members of that group. According to Casey, not only students but faculty from a low class background as well might, in their struggle to advance their career by conforming to middle class norms and values, shy away in the dialogue from revealing their roots. While Casey (2005) worries about the freedom and desire to share from a class perspective, Ladson-Billings (1999) worries about this issue from a racial perspective since the mode of communication is different among White students and Black students and this could cause dissonance and misunderstanding in a way that is not conducive to learning. For example, Ladson-Billings (1999) maintains that when Black students are angry, they become loud and vocal while White students resort to silence in such a way that can deceive the educator to think that they are in compliance with what is being taught while in reality they are hiding deep emotions within. Matusov et al.'s study (2007) suggests Latino students to be reticent because of their distrust of their White educators. Furthermore, Matusov (2009) worries about the issue of excessive dialogicity among certain marginalized ethnic groups whose identity has been obliterated by several forms of oppression historically and contemporarily that they have not learned to develop a clear and distinct voice backed by a community that affirms it and gives it legitimacy. In the context of dialogic multicultural education, the absence of the voices of minority students could be a problem in depriving the dialogue from the experiential knowledge of these students; however, could the presence of such minorities offer these experiences in light of their socialization and education within a society that could have masked their ethnic identity in favor of allowing them to pass as White and thus to succeed academically and socially (Fordham, 1993; Fordham \& Ogbu, 1986; Gayles, 2005)? This issue requires more research in the context of dialogic pedagogy and multicultural education.

The last challenge for dialogic pedagogy is the nature of the institution of conventional education. There seems to be skepticism among some Bahktinian scholars and others (DePalma, 2010; Giroux, 2010; Matusov, 2009) that such an approach could be possible in the setting of conventional education with its emphasis on hierarchical relationships among students and teachers, teachers and administrators, and teachers, administrators and the sociopolitical context of the wider society. Despite claims in the field of education that dialogic class discussions could produce better school achievement and improve students' performance and engagement, from a Bakhtinian dialogic perspective, what takes 
place in the majority of these studies is far from an authentic dialogue and is another attempt toward a banking education that places teachers and students in an erroneous role of experts and knowledge receptors. In the field of multicultural education and despite claims that multiculturalism is a reform movement that seeks equal educational opportunities, a monologic discourse has been prevalent in the policies, practices, and research regarding this area. However, in dialogic pedagogy, with its emphasis on freedom of expression and freedom of association, how could assessment take place or could it take place in any way that could satisfy institutional requirements? This is an issue for further investigation.

\section{Conclusion}

Bakhtinian dialogic pedagogy in critical multicultural education in the conventional higher institution is an educational approach that promises for learning to occur within a community of learners in which students contribute to the class discourse through their own subjectivity, histories, past educational experiences, and the authoritative word they bring to the discourse. The monologism of the standardized movement in education, the policies of the institution, and the hierarchical structure of conventional education represent major challenges for such dialogue. Since dialogue is essentially relational (Sidorkin, 1999), educators could expect that relationships among class members could hinder or enhance the class dialogue and in turn the quality of learning that takes place. Thus, as opposed to conventional educational research that focuses on the relationship between teachers and students, more research needs to be conducted to investigate relationships among students and how it could be better developed to enhance learning. These relationships need to be investigated both within the classroom and beyond the classroom setting because in an authentic dialogic project, educators and researchers should expect the dialogue to continue and to penetrate students' lives beyond the institution.

Furthermore, since dialogic pedagogy offers the opportunity for an internally persuasive discourse (Matusov, 2009) in which knowledge becomes contextualized, historicized, and integrated within an interconnected network of relationships and propositions, dialogic pedagogy promises much learning to take place; however, it is the kind of learning that is mainly authored and controlled by the students rather than the instructors' lesson plans or curricular endpoints. Thus, new methods of assessment that move away from quantifiable learning objectives need to be investigated to judge the success or failure of such an approach in multicultural education.

\section{References}

Amos, Y. T. (2010). "They Don't Want to Get It!" Interaction between minority and White pre-service teachers in a multicultural education class. Multicultural Education, 17(4), 31-37.

Bakhtin, M. M. (1991). Dialogic imagination: Four essays by M. M. Bakhtin. Austin, TX: University of Texas Press.

Banks, J. A. (1994). An introduction to multicultural education. Needham Heights, MA: Library of Congress.

Bennett, W. (1992). The de-valuing of America. New York, NY: Summit Books.

Bergerson, A. A. (2003). Critical race theory and white racism: Is there room for white scholars in fighting racism in education? International Journal of Qualitative Studies in Education, 16(1), 51-63. doi: $10.1080 / 0951839032000033527$ 
Brown, R., \& Renshaw, P. (2006). Positioning students as actors and authors: A chronotopic analysis of collaborative learning activities. Mind, Culture, and Activity 13(3), 247 - 259.

Caldéron, D. (2006). One-dimensionality and Whiteness. Policy Futures in Education, 4(1), 73-82.

Candela, A. (1999). Students' power in classroom discourse. Linguistic and Education, 10(2), 139-163.

Casey, J. G (2005). Diversity, discourse, and the working- class student. Academe, 91(4), 33-36.

Chávez - Reyes, C. (2010). Critical liberal education: An undergraduate pedagogy for teacher candidates in socially diverse university settings. Teaching Education, 21(3), 297-311. doi: 10.1080/10476210903420072

Cuenca, A. (2010). Democratic means for democratic ends: The possibilities of Bakhtin's dialogic pedagogy for social studies. The Social Studies, 102(1), 42-48. doi: 10.1080/00377996.2010.484442

Delgado, R., \& Stefancic, J. (2011). Critical race theory: An introduction. New York, NY: NYU Press.

Delpit, L. (1988). The silenced dialogue: Power and pedagogy in educating other people's children. Harvard Education Review, 58(3), 280-298.

Delpit, L. (1995). Other people's children: Cultural conflict in the classroom. New York, NY: Norton \& Company, Inc.

DePalma, R. (2007). 'She went too far': civility, complaint and dialoguing with the Other Marginality and Difference in Education and Beyond (pp. 121-133). Sterling, VA: Trentham Books Limited.

DePalma, R. (2008). "The voice of every Black person"? Bringing authentic minority voices into the multicultural dialogue. Teaching and Teacher Education, 24(3), 767-778. doi: 10.1016/j.tate.2007.08.002

DePalma, R. (2010). Toward a practice of polyphonic dialogue in multicultural teacher education. Curriculum Inquiry, 40(3), 436-453. doi: 10.1111/j.1467-873X.2010.00492.x

DePalma, R, Santos Rego, M., \& del Mar Lorenzo Moledo, M. (2006). Not just any direct experience will do: Recasting the multicultural teaching practicum as active, collaborative and transformative. Intercultural Education, 17(4), 327-339. doi: 10.1080/14675980600971293

Ellsworth, E. (1989). Why doesn't this feel empowering? Working through the repressive myths of critical pedagogy. Harvard Educational Review, 59(3), 297-324.

Facundo, B. (1984). Freire inspired programs in the United States and Puerto Rico: A critical evaluation. http://www.bmartin.cc/dissent/documents/Facundo/bibliography.html

Fecho, B., Collier, N. D., Friese, E.G., \& Wilson, A. A. (2010). Critical conversations: Tensions and opportunities of the dialogic classroom. English Education, 42(4), 427-447.

Fordham, S. (1993). Those loud Black girls: Black women, silence, and gender "passing" in the academy. Anthropology and Education Quarterly, 24(1), 3-32.

Fordham, S, \& Ogbu, J. (1986). Black students' school success: Coping with the "burden of 'acting white'". The Urban Review, 18(3).

Freire, P. (1993). The pedagogy of the oppressed. New York, NY: The Continuum International Publishing Group Inc. 
Freire, P., \& Macedo, D. (1987). Literacy: Reading the word \& the world. South Hadley, Mass: Bergin \& Garvey Publishers.

Gardiner, M. (2002). The dialogics of critique: M.M. Bakhtin and the theory of ideology. New York, NY: Routledge.

Gayles, J. (2005). Playing the game and paying the price: Academic resilience among three highachieving African American males. Anthropology \& Education Quarterly, 36(3), 250-264.

Giroux, H. A. (2010). Bare pedagogy and the scourge of neoliberalism: Rethinking higher education as a democratic public sphere. The Educational Forum, 74(3), 184-196. doi: $10.1080 / 00131725.2010 .483897$

Hirsch, E.D. (1987). Cultural literacy: What every American needs to know. Boston, MA: Houghton.

Holins, E., \& Guzman, M.T. (2005). Research on preparing teachers for diverse populations. Studying teacher education: The report of the AERA panel on research and teacher education, 477-548.

Kohli, R. (2008). Breaking the cycle of racism in the classroom: Critical race reflections from future teachers of color. Teacher Education Quarterly, 35(4), 177-188.

Kukathas, C. (2003). The liberal archipelago: A theory of diversity and freedom. New York, NY: Oxford University Press.

Ladson-Billings, G. (1999). Preparing teachers for a diverse student populations: A critical race theory perspective. Review of Research on Education, 24, 211-247.

Ladson-Billings, G, \& Tate, W. (1995). Toward a critical race theory of education. Teachers College Record 97(1), 47-68.

Ladson-Billings, G, \& Tate, W. F. (2006). Education research in the public interest : social justice, action, and policy. New York: Teachers College Press.

Lee, E. (1995). Taking multicultural and anti-racist education seriously: An interview with Enid Lee. Rethinking schools: An agenda for change 9-16.

Madison, D. S. (2011). Critical ethnography: Method, ethics, and performance. Thousand Oaks, CA: Sage Publications.

Martin, K. J. (2010). Student attitudes and the teaching and learning of race, culture and politics. Teaching and Teacher Education: An International Journal of Research and Studies, 26(3), 530539.

Mattai, P. R. (1992). Rethinking the nature of multicultural education: Has it lost its focus or is it being misused? The Journal of Negro Education, 61(1), 65-77.

Matusov, E. (2009). Journey into dialogic pedagogy. New York, NY: Nova Science Publishers.

Matusov, E. (2011). Authorial teaching and learning. In E. J. White \& M. Peters (Eds.), Bakhtinian pedagogy: Opportunities and challenges for research, policy and practice in education across the globe (pp. 21-46). New York, NY: Peter Lang Publishers.

Matusov, E, Pleasants, H., \& Smith, M. (2003). Dialogic framework for cultural psychology: Culture-inaction and culturally sensitive guidance. Review Interdisciplinary Journal on Human Development, Culture and Education, 4(1).

Matusov, E., Hayes, R., \& Pluta, M. J. (2005). Using discussion worldwide webs to develop an academic community of learners. Educational Technology \& Society, 8(2), 16-39. 
Matusov, E., \& Smith, M. P. (2007). Teaching imaginary children: University students' narratives about their Latino practicum children. Teaching and Teacher Education, 23(5), 705-729. doi: 10.1016/j.tate.2005.09.012

Milner, H. R. (2008). Critical race theory and interest convergence as analytic tools in teacher education policies and practices. Journal of Teacher Education, 24(6), 1573-1598.

Morson, G. (2004). The process of ideological becoming. In A. F. Ball \& S. W. Freedman (Eds.), Bakhtinian perspectives on language, literacy, and learning (pp. 317-331). Cambridge, UK: Cambridge University Press.

Nieto, S. (2004). Affirming diversity: The sociopolitical context of multicultural education. New York, NY: Longman.

Ogbu, J. (2008). Minority status, oppositional culture, \& schooling. New York. NY: Routledge.

Shor, I. (1992). Empowering education: Critical teaching for social change. Chicago, Ilinois: The University of Chicago Press.

Shor, I, \& Freire, P. (1987). What is the "dialogical method" of teaching? Journal of Education, 169(3), 1131.

Sidorkin, A. M. (1999). Beyond discourse: Education, the self, and dialogue. Albany, N.Y.: State University of New York Press.

Sleeter, C.E. (1995). White preservice students and multicultural education coursework. In J. M. Larkin \& C. E. Sleeter (Eds.), Developing multicultural teacher education curricula (pp. 17-29). Albany, NY: State University of New York Press.

Sleeter, C.E., \& Bernal, D.D. (2003). Critical pedagogy, critical race theory, and antiracist education: Implications for multicultural education. In J.A.Banks \& C. A. Banks (Eds.), Handbook of research on multicultural education, 2nd edn. San Francisco, CA: Jossey-Bass.

Solomon, R. P., Portelli, J. P., Daniel, B. J., \& Campbell, A. (2005). The discourse of denial: How white teacher candidates construct race, racism and 'white privilege'. Race, Ethnicity and Education, 8(2), 147-169. doi: 10.1080/13613320500110519

Solorzano, D. (1997). Images and words that wound: Critical race theory, racial stereotyping, and teacher education. Teacher Education Quarterly, 24(3), 5-19.

Stovall, D. (2004). School leader as negotiator: Critical race theory, praxis, and the creation of productive space. Multicultural Education, 12(2), 8-12.

Sullivan, P. (2011). Qualitative data analysis using a dialogical approach. Thousand Oaks, CA: SAGE.

Taylor, E., Gillborn, D., \& Ladson-Billings, G. (2009). Foundations of critical race theory in education. New York: Routledge.

Whitlock, R. U. (2010). Getting queer: Teacher education, gender studies, and the cross disciplinary quest for queer pedagogies. Issues in Teacher Education, 19(2), 81-105.

Yang, Y, \& Montgomery, D. (2013). Gaps or bridges in multicultural teacher education: A Q study of attitudes toward student diversity. Teaching and Teacher Education, 30, 27-37. doi: 10.1016/j.tate.2012.10.003

Yosso, T. (2002). Toward a critical race curriculum. Equity and Excellence in Education, 35(2), 93-107. 


\section{Acknowledgements}

I'd like to thank Dr. Eugene Matusov, my dissertation advisor and academic mentor, for inspiring this work through his commitment to continued dialogue and non-hierarchical academic relationships. I'd also like to thank members of the Professional Inquiry Group at the University of Delaware especially Dr. Ana Marjanovic-Shane, Dr. Kathy Von Duyke, Samanta Lopez, Bryan Campbell, and Lei Chen for providing their viewpoints and for inciting dialogic provocations to think about and to reflect on the issues raised in this article.

\section{(c)) EY}

New articles in this journal are licensed under a Creative Commons Attribution 4.0 United States License.

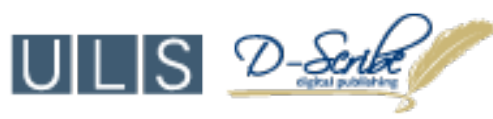

This journal is published by the University Library System, University of Pittsburgh as part of its D-Scribe Digital Publishing Program and is cosponsored by the University of Pittsburgh Press. 